\title{
ANALISIS KANDUNGAN LOGAM BERAT TIMBAL (Pb) PADA JAJANAN GORENGAN DI KOTA MAKASSAR
}

A Nurul Fitrah Kahar Bella ${ }^{1}$, Erlani²

1,2 Jurusan Kesehatan Lingkungan Politeknik Kesehatan Kemenkes Makassar

(anurulfitrahkaharbella@gmail.com)

\begin{abstract}
Lead is dust particles produced from transitional vehicle emissions. Lead $(\mathrm{Pb})$ is a metal that gets attention because it is poisonous through food, drink, air, water, and dust contaminated with $\mathrm{Pb}$. Pb intocisitation can occur through the oral route, through food, and drinks. The purpose of this study was to determine the levels of lead $(\mathrm{Pb})$ in fried snacks in Makassar City. This study uses observational using descriptive. The number of samples used were 24 samples, namely bakwan fried samples, banana fried samples and cooking oil samples taken at the same location. Data obtained from observations in the field and laboratory tests in this study will be presented in table form. The results showed that the average lead content (Pb) in fried snacks in Makassar City for the value of lead level (Pb) was the highest bakwan fried food, which was $6.3397 \mathrm{mg} / \mathrm{kg}$, for the fried banana sample the highest lead $(\mathrm{Pb})$ value was $8,7637 \mathrm{mg} / \mathrm{kg}$ and for cooking oil samples used the value of lead $(\mathrm{Pb})$ is $<0.10 \mathrm{mg} / \mathrm{kg}$. The conclusion in this study is that lead content $(\mathrm{Pb})$ in fried snacks in the City in accordance with the regulations does not meet the requirements for fried snacks based on BPOM RI Number HK.00.06.1.52.4011 which is 0.25 $\mathrm{mg} / \mathrm{kg}$. and examination of lead $(\mathrm{Pb})$ content in cooking oil fulfills the requirements in accordance with the provisions of SN $01-3741-2002$, namely $0.1 \mathrm{mg} / \mathrm{kg}$. It is expected that street vendors who sell on the side of the road so that fried snacks are sold under closed conditions to minimize exposure to lead $(\mathrm{Pb})$.
\end{abstract}

Keywords: Lead $(\mathrm{Pb})$, Fried, Cooking Oil

\section{ABSTRAK}

Timbal adalah partikel-partikel debu yang dihasilkan dari emisi kendaraan bermotor. Timbal $(\mathrm{Pb})$ adalah logam yang mendapat perhatian karena bersifat toksik melalui makanan, minuma, udara, air, serta debu yang tercemar timbal. Inseksitas timbal bisa terjadi melalui jalur oral, lewat makanan, dan minuman. Tujuan dari penelitian ini adalah untuk mengetahui kadar timbal pada jajanan gorengan di Kota Makassar. Penelitian ini menggunakan observasional pendekatan deskriptif. Jumlah sampel yang digunakan adalah 24 sampel yakni sampel gorengan bakwan, sampel gorengan pisang dan sampel minyak goreng yang diambil pada delapan lokasi yang sama. Data yang diperoleh dari hasil observasi dilapangan dan pemeriksaan laboratorium dalam penelitian ini akan disajikan dalam bentuk tabel. Hasil penelitian menunjukkan bahwa rata-rata kandungan timbal pada jajanan gorengan di Kota Makassar untuk nilai kadar timbal tertinggi gorengan bakwan yaitu 6,3397 mg/kg, untuk sampel gorengan pisang nilai kadar timbal tertinggi yaitu $8,7637 \mathrm{mg} / \mathrm{kg}$ dan untuk sampel minyak goreng yang digunakan nilai kadar timbal yaitu $<0,10 \mathrm{mg} / \mathrm{kg}$. Kesimpulan dalam penelitian ini yaitu kandungan timbal pada jajanan gorengan di Kota Makassar sesuai dengan peraturan tidak memenuhi syarat untuk jajanan gorengan berdasarkan BPOM RI Nomor HK.00.06.1.52.4011 yaitu $0.25 \mathrm{mg} / \mathrm{kg}$. dan pemeriksaan kandungan timbal pada minyak goreng memenuhi syarat sesuai dengan peraturan berdasarkan SNI 01-3741-2002 yaitu 0,1 mg/kg. Diharapkan bagi pedagang kaki lima yang menjual dipinggir jalan agar jajanan gorengan yang dijual dalam kondisi tetutup untuk meminimalir terpaparnya timbal.

Kata Kunci : Timbal (Pb), Gorengan, Minyak Goreng

\section{PENDAHULUAN}

Makanan merupakan hal yang sangat penting dalam kehidupan kita bahkan setiap hari kita akan membutuhkannya, maka dari itu makanan harus terjaga baik itu dari kualitas dan segi pencemaran dari makanan yang dikonsumsi agar tidak terjadi penyakit pada saat memakan makanan yang dikonsumsi baik itu keterpaparan secara langsung atau tidak.

Seiring dengan kemajuan zaman, banyak orang yang tidak sempat menyiapkan sendiri makanan yang akan dikonsumsi. Dengan demikian mereka bergantung pada pelayanan jaga boga untuk memenuhi kebutuhan makanannya. Kenyataan ini juga mendorong semakin tumbuh berkembangnya institusi pelayanan jasa boga seperti warung makan, restoran, catering, bahkan warung tenda dan lesehan yang melayani banyak orang. Pelayanan jasa boga ini memiliki tanggungjawab yang besar dalam meyediakan makanan yang berkualitas yaitu enak, kompotitif dalam harga dan aman untuk di konsumsi. (Sri Wahyuni, 2011).

Terkait dengan penyediaan makanan untuk umum, di Kota Makassar ada beberapa jenis penjual makanan, salah satu jenis makanan yang dijual adalah jajanan gorengan seperti tahu, tempe, pisang yang diolah dengan menggunakan terigu dan minyak goreng dan merupakan makanan yang sangat diminati masyarakat karena disamping enak, makanan ini juga harganya terjangkau dan mudah di dapat.

Makanan jajanan gorengan yang banyak dijual di pinggir jalan tidak menutup kemungkinan dapat terpapar oleh asap kendaraan bermotor dan kita ketahui bahwa asap kendaraan bermotor mengandung timbal (Pb), data menunjukkan bahwa kendaraan di Kota Makassar semakin tahun meningkat pada tahun 2007 sebanyak 306.341 unit, tahun 2008 sebanyak 360.122 unit, tahun 2009 sebanyak 449.588 unit dan tahun 2010 sampai bulan juli sebesar 587.206 unit, peningkatan jumlah ini sebesar $20 \%$ pertahunnya, sedangkan jumlah kendaraan roda empat meningkat sekitar 15\% setiap tahunnya. Pada tahun 2009 sebanyak 79.266 unit dan tahun 2010 sampai bulan juli sebesar 89.642 unit. (Sri Wahyuni, 2011).

Hasil survei awal yang dilakukan di Kota Makassar pada bulan Desember ada beberapa penjual gorengan yang ada di wilayah Makassar yaitu Lanto Dg. Pasewang 1 penjual, Datuk 
Patimang 3 penjual, Toddopuli 5 penjual, Cendrawasi 4 penjual, $\mathrm{Dg}$ Tata 5 penjual, Alauddin 3 penjual, Daya 13 penjual, Pabaengbaeng 2 penjual, Mallengkeri 3 Penjual, Minasa Upa 5, Sunu 4 penjual, Rappocini 3 penjual dan Lamuru 5 penjual, Abdullah dg. Sirua. Biasanya mereka menjual jajanan gorengan waktu pagi sampai malam dan ada juga yang menjual pada waktu pagi, sore sampai malam dengan lama waktu pemajanan dapat mengakibatkan jajanan tersebut terpapar oleh timbal $(\mathrm{Pb})$ karena jajanan yang dijual tersebut dalam kedadaan terbuka dari hasil observasi terhadap pedagang jajanan gorengan di jalan Datuk Patimang, Lanto Dg. Pasewang, Toddopuli, Minasa Upa, Daya, Daeng Tata, Cendrawasih, Sunu Kota Makassar umumnya dalam menjajakan gorengan dalam keadaan terbuka sehingga tidak menutup kemungkinan tercemarnya timbal (Pb) maka penulis mengambil titik sampel di daerah Kota Makassar. (November 2018)

Berdasarkan penelitian Ardalina, Wirsal Hasan dan Indra Chaya (2012) di Kota Medan analisa kadar timbal pada gorengan yaitu 1.0498 ppm. Dan berdasarkan penelitian Sri Wahyuni (2011) untuk mengetahui kadar timbal $(\mathrm{Pb})$ pada jajanan gorengan yang ada disekitar Pasar Sentral Kota Makassar yaitu (Pb) tahu 0,89 $\mathrm{mg} / \mathrm{kg}$, tempe $0,49 \mathrm{mg} / \mathrm{kg}$ dan bakwan 0,58 $\mathrm{mg} / \mathrm{kg}$. Besarnya dan akumulasi logam berat $\mathrm{Pb}$ dapat masuk ke dalam tubuh melalui makanan jajanan yang dijual dan diolah di pinggir jalan dalam keadaan terbuka menurut penelitian Risma, Anwar Mallongi, Erniwati (2015) kandungan logam berat timbal $(\mathrm{Pb})$ gorengan dipinggir jalan kacamatan Tallo yaitu yaitu 0,057 $\mathrm{mg} / \mathrm{kg}-1,537 \mathrm{mg} / \mathrm{kg}$.

Berdasarkan latar belakang diatas maka penulis merasa perlu melakukan penelitian tentang analisis kadar timbal $(\mathrm{Pb})$ pada gorengan di Kota Makassar.

\section{METODE}

\section{Desain, tempat, dan waktu}

Penelitian yang dilakukan ini merupakan penelitian Observasional dengan pendekatan deskriptif untuk mengetahui seberapa besar kandungan logam berat timbal (Pb) yang terdapat pada makanan gorengan yang dijual dipinggir jalan Kota Makassar.Untuk mengetahui kadar timbal $\mathrm{Pb}$ pada makanan gorengan dilakukan uji laboratorium. Adapun lokasi penelitian ini untuk pengambilan sampel jajanan gorengan di dilakukan yaitu di jalan Datuk Patimang, Lanto Dg. Pasewang, Toddopuli, Minasa Upa, Daya, Deng Tata, Cendrawasi, Sunu di Kota Makassar.

\section{Populasi dan Sampel}

Populasi dalam penelitian ini adalah seluruh penjual jajanan gorengan di Kota Makassar yang berjumlah 70 . Teknik penentuan pengambilan sampel yang digunakan pada pemilihan lokasi pengambilan sampel jajanan gorengan bakwan, pisang dan minyak goreng yaitu teknik purposive sampel sebanyak 24 sampel.

\section{Pengumpulan Data}

Data primer diperolah dengan melakukan observasi langsung terhadap penjual gorengan dan melakukan pemeriksaan di Laboratorium. Data sekunder yang dimaksud adalah data-data instansi yang terkait berupa buku-buku literature, skripsi dan bahan bacaan lainnya yang ada hubungannya dengan penelitian.

\section{Pengolahan dan Analisis Data}

Data yang diperoleh dari hasil observasi di lapangan dan hasil Laboratorium dalam penelitian ini akan diolah dengan menggunakan computer dan kalkulator. Data yang telah diolah disajikan dalam bentuk tabel dan narasi kemudian dianalisa secara deskriptif.

\section{HASIL}

Penelitian ini dilaksanakan pada Bulan Januari sampai dengan April 2019. Pengambilan sampel penelitian ini dilaksanakan di jalan-jalan Kota Makassar dimana terdapat delapan lokasi pengambilan sampel untuk gorengan dan minyak goreng.

Pengambilan sampel gorengan dan minyak goreng dilakukan pada delapan lokasi pengambilan sampel yaitu sampel pertama diambil di jalan Datuk Patimang, sampel kedua diambil di jalan Lanto Dg Pasewang, sampel ketiga diambil di jalan Toddopuli, sampel keempat diambil di jalan Minasa Upa, sampel kelima diambil di jalan Daya, sampel keenam diambil di jalan Daeng Tata, sampel ketujuh diambil di jalan Cendrawasih, sampel kedelapan diambil di jalan Sunu.

Di lokasi penelitian merupakan jalanan yang padat akan kendaraan namun banyaknya penjual jajanan gorengan yang tidak tetutup. Namun terbukanya jualan jajanan gorengan tersebut sangat berisiko terkontaminasi oleh timbal $(\mathrm{Pb})$ ada tiga sumber kontaminasi $\mathrm{Pb}$ pada makanan, yaitu pencemaran udara berupa emisi gas buangan kendaraan bermotor, peralatan dapur, serta kertas kemasan dan nonkemasan, seperti kertas koran dan majalah. Diperkirakan hampir $90 \%$ timbal (Pb) yang masuk ke dalam tubuh manusia berasal dari makanan.

Analisis kandungan logam berat timbal $(\mathrm{Pb})$ pada jajanan gorengan dan minyak goreng dilaksanakan di Balai Besar Industri Hasil Perkebunan (BBIHP), dan dilaksanakan secara 
bersamaan dengan jumlah 16 sampel yaitu gorengan, dan 8 minyak goreng. Sampel ini diperiksa pada tanggal 21 Januari 2019.

Tabel 1

Kandungan Timbal $(\mathrm{Pb})$ pada Gorengan Bakwan di Kota Makassar Tahun 2019

\begin{tabular}{|c|c|c|c|}
\hline No. & $\begin{array}{c}\text { Tempat } \\
\text { Pengambilan } \\
\text { Sampel }\end{array}$ & $\begin{array}{c}\text { Kadar } \\
\text { Timbal } \\
(\mathrm{Pb})\end{array}$ & Keterangan \\
\hline 1. & $\begin{array}{ll}\text { Jl. } & \text { Datuk } \\
\text { Patimang }\end{array}$ & $\begin{array}{c}0,7570 \\
\mathrm{mg} / \mathrm{kg}\end{array}$ & TMS \\
\hline 2. & $\begin{array}{l}\text { Jl. Lanto Dg. } \\
\text { Pasewang }\end{array}$ & $\begin{array}{l}0,6653 \\
\mathrm{mg} / \mathrm{kg}\end{array}$ & TMS \\
\hline 3. & Jl. Toddopuli & $\begin{array}{l}<0,10 \\
\mathrm{mg} / \mathrm{kg}\end{array}$ & MS \\
\hline 4. & Jl. Minasa Upa & $\begin{array}{l}6,3397 \\
\mathrm{mg} / \mathrm{kg}\end{array}$ & TMS \\
\hline 5. & Jl. Daya & $\begin{array}{l}0,4518 \\
\mathrm{mg} / \mathrm{kg}\end{array}$ & TMS \\
\hline 6. & Jl. Daeng Tata & $\begin{array}{l}<0,10 \\
\mathrm{mg} / \mathrm{kg}\end{array}$ & TMS \\
\hline 7. & Jl. Cendrawasi & $\begin{array}{l}0,2368 \\
\mathrm{mg} / \mathrm{kg}\end{array}$ & MS \\
\hline 8. & Jl. Sunu & $\begin{array}{l}<0,10 \\
\mathrm{mg} / \mathrm{kg}\end{array}$ & MS \\
\hline
\end{tabular}

Tabel 2

\begin{tabular}{|c|c|c|c|}
\hline \multicolumn{4}{|c|}{$\begin{array}{c}\text { Kandungan Timbal (Pb) pada Gorengan Pisang di } \\
\text { Kota Makassar Tahun } 2019\end{array}$} \\
\hline No. & $\begin{array}{c}\text { Tempat } \\
\text { Pengambilan } \\
\text { Sampel }\end{array}$ & $\begin{array}{c}\text { Kadar } \\
\text { Timbal }(\mathrm{Pb})\end{array}$ & Keterangan \\
\hline 1. & Jl. Datuk Patimang & $<0,10 \mathrm{mg} / \mathrm{kg}$ & MS \\
\hline 2. & $\begin{array}{l}\text { Jl. Lanto Dg. } \\
\text { Pasewang }\end{array}$ & $\begin{array}{c}3,7499 \\
\mathrm{mg} / \mathrm{kg}\end{array}$ & TMS \\
\hline 3. & Jl. Toddopuli & $<0,10 \mathrm{mg} / \mathrm{kg}$ & MS \\
\hline 4. & Jl. Minasa Upa & $\begin{array}{c}0,5573 \\
\mathrm{mg} / \mathrm{kg}\end{array}$ & TMS \\
\hline 5. & Jl. Daya & $\begin{array}{l}1,0186 \\
\mathrm{mg} / \mathrm{kg}\end{array}$ & TMS \\
\hline 6. & Jl. Daeng Tata & $\begin{array}{l}8,7637 \\
\mathrm{mg} / \mathrm{kg}\end{array}$ & TMS \\
\hline 7. & Jl.Cendrawasi & $\begin{array}{c}0,3071 \\
\mathrm{mg} / \mathrm{kg}\end{array}$ & TMS \\
\hline 8. & Jl. Sunu & $<0,10 \mathrm{mg} / \mathrm{kg}$ & MS \\
\hline
\end{tabular}

Tabel 3

Kandungan Timbal $(\mathrm{Pb})$ pada Minyak Goreng di Kota Makassar Tahun 2019

\begin{tabular}{|c|c|c|c|c|}
\hline $\begin{array}{l}\mathbf{N} \\
\mathbf{0}\end{array}$ & $\begin{array}{c}\text { Tempat } \\
\text { Pengambilan } \\
\text { Sampel }\end{array}$ & $\begin{array}{c}\text { Jenis } \\
\text { (MK/M } \\
\text { C) }\end{array}$ & $\begin{array}{l}\text { Kadar } \\
\text { Timbal } \\
\text { (Pb) }\end{array}$ & Ket \\
\hline 1 & $\begin{array}{l}\text { Jl. Datuk } \\
\text { Patimang }\end{array}$ & MK & $\begin{array}{l}<0,10 \\
\mathrm{mg} / \mathrm{kg}\end{array}$ & MS \\
\hline 2 & $\begin{array}{l}\text { Jl. Lanto Dg. } \\
\text { Pasewang }\end{array}$ & MC & $\begin{array}{l}<0,10 \\
\mathrm{mg} / \mathrm{kg}\end{array}$ & MS \\
\hline 3 & Jl. Toddopuli & MC & $\begin{array}{l}<0,10 \\
\mathrm{mg} / \mathrm{kg}\end{array}$ & MS \\
\hline 4 & Jl. Minasa Upa & MK & $\begin{array}{l}<0,10 \\
\mathrm{mg} / \mathrm{kg}\end{array}$ & MS \\
\hline 5 & J. Daya & MK & $\begin{array}{l}<0,10 \\
\mathrm{mg} / \mathrm{kg}\end{array}$ & MS \\
\hline 6 & Jl. Daeng Tata & MK & $\begin{array}{l}<0,10 \\
\mathrm{mg} / \mathrm{kg}\end{array}$ & MS \\
\hline 7 & Jl. Cendrawasi & MC & $\begin{array}{l}<0,10 \\
\mathrm{mg} / \mathrm{kg}\end{array}$ & MS \\
\hline 8 & J. Sunu & MC & $<0,10$ & MS \\
\hline
\end{tabular}

$$
\begin{aligned}
& \text { Keterangan: } \\
& \text { MK } \quad=\text { Minyak Kemasan } \\
& \text { MC } \quad=\text { Minyak Curah } \\
& \text { MS } \quad=\text { Meenuhi syarat } \\
& \text { TMS } \quad=\text { Tidak memenuhi syarat }
\end{aligned}
$$

\section{PEMBAHASAN}

\section{1) Kandungan Timbal (Pb) pada Gorengan Bakwan di Kota Makassar}

Berdasarkan hasil analisis kandungan timbal $(\mathrm{Pb})$ yang di deteksi pada jajanan gorengan bakwan. Hasill analisis kandungan timbal $(\mathrm{Pb})$ dalam jajanan gorengan di kota Makassar tidak memenuhi syarat, hal tersebut didasarkan pada ketentuan baku mutu kandungan logam berat pada cemaran mikroba dan kimia dalam makanan pada pangan olahan lainnya yaitu kandungan timbal $(\mathrm{Pb})$ sebagai pencemaran dalam pangan dan olahan lainnya maksimal 0,25 $\mathrm{mg} / \mathrm{kg}$ menurut Peraturan Kepala Badan Pengawasan Obat dan Makanan Republik Indonesia Nomor HK.00.06.1.52.4011.

Berdasarkan penelitian dari Miranti Reski Amalia (2017) di jalan Daeng Tata Raya makanan yang diperiksa adalah ubi goreng yaitu $0,0868 \mathrm{mg} / \mathrm{kg}$. Kadar timbal $(\mathrm{Pb}) \mathrm{di}$ alam sangat bervariasi tetapi kandungan dalam tubuh manusia berkisar antara $100-$ $400 \mathrm{mg}$. sumber masukan timbal $(\mathrm{Pb})$ adalah makanan terutama bagi mereka yang tidak bekerja atau kontak dengan timbal $(\mathrm{Pb})$ di perkirakan rata-rata masuk timbal $(\mathrm{Pb})$ melalui makanan adalah $300 \mu \mathrm{g}$ perhari dengan kisaran antara 100-500 mg perhari.

Adanya perbedaan kandungan timbal $(\mathrm{Pb})$ pada setiap pada setiap jajanan gorengan Kontiminasi timbal juga terjadi dalam rumah kita sendiri, dari pipa air yang berkarat. Lebih mengkhawatirkan karena timbal dapat terakumulasi dalam setiap makluk hidup dan keseluruhan rantai makanan. Manusia dapat terkontaminasi logam berbahaya ini melalui makanan (65\%), air (20\%), maupun udara (15\%). Sementara itu diketahui bahwa timbal tidak memiliki fungsi apapun bagi tubuh manusia. Jadi penyerapan timbal melalui makanan, air, udara hanyalah menimbulkan kerugian saja (Wardhana, 2001).

Penelitian oleh Hendra Gunawan, dkk (2016) Hasil pengukuran konsentrasi $\mathrm{Pb}$ diketiga lokasi penelitian berkisar antara0,375-1,600 $\mu \mathrm{g} / \mathrm{Nm3}$. Konsentrasi rata-rata tertinggi terdapat pada Jl. Bagindo Aziz Chan sebesar 1,039 $\mu \mathrm{g} / \mathrm{m} 3$ diikuti oleh Jl. Perintis Kemerdekaan sebesar 0,917 
$\mu \mathrm{g} / \mathrm{m} 3$ dan dan Jl. Raya By Pass sebesar $0,826 \mu \mathrm{g} / \mathrm{m} 3$. Kendaraan sepeda motor dan kendaraan ringan ini umumnya menggunakan bahan bakar bensin, yang merupakan sumber dari emisi $\mathrm{Pb}$ di jalan raya akibat dari pembakaran bahan bakar dalam mesin kendaraan.

Makanan pinggir jalan adalah salah contoh makanan yang berisiko tercemar timbal (Pb). Beberapa kalangan, khususnya kalangan yang sangat memperhatikan gizi dari setiap makanan yang dikonsumsi, melihat bahwa makanan pinggir jalan khususnya gorengan, sebenarnya adalah makanan sangat berbahaya bagi kesehatan. Salah satu alasannya adalah faktor kondisi sekitar pedagang gorengan yang menjadi penyebab gorengan menjadi tidak sehat untuk dikonsumsi (Sri Ulandari, dkk, 2016).

Berdasarkan hasil analisa kandungan timbal $(\mathrm{Pb})$ yang di deteksi pada jajanan gorengan bakwan. Hasil analisa kandungan timbal $(\mathrm{Pb})$ dalam jajanan gorengan bakwan pada lokasi jl. Minasa Upa adalah jumlah kadar $\mathrm{Pb}$ paling tertinggi yaitu $6,3397 \mathrm{mg} / \mathrm{kg}$.

Palar (2004) mengatakan bahwa memang sudah ada beberapa studi yang menyebutkan adanya kontaminasi timbal (Pb) pada makanan olahan dan makanan kaleng serta makanan yang telah diasamkan dapat melarutkan timbal (Pb) dari wadah atau alat-alat pengolahannya. Beberapa studi terbatas juga telah menemukan timbal $(\mathrm{Pb})$ pada daun tumbuhan.

Makan di pinggir jalan beresiko cukup tinggi untuk menyebabkan penyakit. Banyak wabah penyakit di Indonesia yang tersebar karena kebiasaan masyarakat untuk makan jajanan sembarangan yang berbahaya di pinggir jalan. Di antaranya adalah penyakit typhus, hepatitis dan keracunan bahan kimia. Meski demikian, terkadang kita kesulitan mencari makan saat di perjalanan atau jika sedang kemalaman. Pilihan yang paling mudah adalah membeli makan di pinggir jalan (Dewi, 2012).

Beberapa kalangan, khususnya kalangan yang sangat memperhatikan gizi dari setiap makanan yang dikonsumsi, melihat bahwa gorengan sebenarnya adalah makanan sangat berbahaya bagi kesehatan. Salah satu alasannya adalah faktor kondisi sekitar pedagang gorengan yang menjadi penyebab gorengan menjadi tidak sehat untuk dikonsumsi.

Pada beberapa kasus belakangan ini terbukti bahwa kemasan pembungkus makanan gorengan juga bisa mengakibatkan cemaran timbal $(\mathrm{Pb})$, terutama kemasan dari koran, majalah dan kertas yang bertinta. Tinta yang mengandung timbal $(\mathrm{Pb})$ dapat dengan mudah berpindah ke dalam makanan akibat kontak dengan panas (Alsuhendra dan Ridawati 2013)

Adapun lokasi pengambilan sampel yaitu di lokasi kedua dan ketiga di jalan Datuk Patimang kadar timbal $(\mathrm{Pb}) \quad 0,7570 \mathrm{mg} / \mathrm{kg}$ dan jalan Lanto Dg. Pasewang kadar timbal $(\mathrm{Pb})$ yaitu $0,6653 \mathrm{mg} / \mathrm{kg}$ karena padatnya kendaraan lalu lintas sehingga dapat terpapar oleh timbal $(\mathrm{Pb})$ yang bersumber dari emisi kendaraan bermotor yang lalu lalang sehingga dapat terakumulasi dengan mengabsorsi ke dalam gorengan sehingga menghasilkan kadar timbal yang tinggi.

Lokasi keempat dan kelima pengambilan sampel yaitu jalan Sunu kadar timbal $(\mathrm{Pb})$ $0,5577 \mathrm{mg} / \mathrm{kg}$ dan jalan Daya kadar timbal (Pb) yaitu 0,4518 $\mathrm{mg} / \mathrm{kg}$ dimana kandungan timbal $(\mathrm{Pb})$ sangat dipengaruhi oleh jumlah kendaraan karena salah satu sumber utama adalah kendaraan bermotor sesuai yang dikemukakan palar dalam buku pencemaran dan toksikologi logam berat tahun 1994 yang mengemukakan bahwa "Emisi $\mathrm{Pb}$ " yang masuk dalam bentuk gas, terutama berasal dari buangan gas kendaraan bermotor.

Adapun lokasi-lokasi yang memiliki jumlah kadar timbal $(\mathrm{Pb})$ yaitu di jalan Cendrawasi kadar timbal (Pb) 0,2368 $\mathrm{mg} / \mathrm{kg}$, di jalan Toddopuli kadar timbal (Pb) yaitu $<0,10 \mathrm{mg} / \mathrm{kg}$ dan jalan Daeng tata kadar timbal $(\mathrm{Pb})$ yaitu $<0,10 \mathrm{mg} / \mathrm{kg}$ jumlah kadar timbal $(\mathrm{Pb})$ di ketiga lokasi tersebut merupakan lokasi jumlah kadar terendah dari semua lokasi, memiliki kadar timbal (Pb) sebagai batas maksimum cemaran mikroba dan kimia dalam makanan maksimal 0,25 $\mathrm{mg} / \mathrm{kg}$ menurut Peraturan Kepala Badan Pengawas Obat dan Makanan RI Nomor HK.00.06.1.52.4011. Namun masih dibawah ambang batas yaitu $0,25 \mathrm{mg} / \mathrm{kg}$. hal tersebut dapat disebabkan beberapa faktor dikarenakan gorengan tersebut baru saja diangkat dari kuali penggorengan dan saat itu masih sangat kurang kendaraan yang berlalu lalang.

Adanya perbedaan kandungan timbal (Pb) pada dalam jajanan gorengan bakwan disebabkan oleh pencemaran udara berupa emisi gas buangan kendaraan bermotor, peralatan dapur, serta kertas kemasan dan nonkemasan, seperti kertas Koran dan majalah. Diperkirakan hampir $90 \% \mathrm{~Pb}$ yang masuk ke dalam tubuh manusia berasal dari makanan. 
Hal ini menunjukkan bahwa logam berat timbal $(\mathrm{Pb})$ dapat mengakumulasi jajanan gorengan disebabkan oleh masih banyaknya digunakan bahan bakar mesin (bensin) kendaraan bermotor yang mengandung $\mathrm{Pb}$, seperti saat ini. Penggunaan $\mathrm{Pb}$ dalam bensin bertujuan untuk mempermudah bensin terbakar. Caranya adalah dengan menurunkan titik bakarnya melalui peningkatan bilangan oktan dengan penambhan timbal dalam bentuk tetra ethyl lead (TEL).

Kondisi tersebut terparah dengan realita bahwa bagian masyarakat yang sering mengonsumsi jajanan gorengan adalah anak-anak sekolah dan mahasiswa yang membutuhkan asupan energi yang lebih dan dan cepat saja karena aktivitas mereka yang padat. Kondisi saat ini adalah banyak pedagang jajanan gorengan yang berjualan dipinggir jalan raya dekat sekolah-sekolah dan kampus-kampus. Apabila hal ini dibiarkan secara terus menerus maka anakanak akan keracunan timbal $(\mathrm{Pb})$ (Anwar dkk 1987).

Meningkatnya kadar timbal $(\mathrm{Pb})$ pada sampel bakwan disebabkan karena bakwan menggunakan bahan campuran kol sedangkan kita ketahui kol yang di tanam tidak menutup kemungkinan terpapar timbal $(\mathrm{Pb})$ dan rata-rata bahan pangan yang ditanam di pinggir jalan terpapar timbal karena bersumber dari kendaraan bermotor yang lalu lalang dan mengabsorsinya dalam jaringan tanaman sehingga akan terbawa saat panen dan selanjutnya pada pengolahan kurang tepat akan dikonsumsi manusia.

Bahan makanan mengandung logam berat sebagai akibat pencemaran secara langsung atau tidak langsung. Sayuran yang yang di jual di pinggir atau dekat dengan jalan raya dan rentan polusi udara mengandung logam berat timbal $(\mathrm{Pb})$ dalam jumlah tinggi, sebuah penelitian menunjukkan bahwa kandungan timbal $(\mathrm{Pb})$ dalam sayuran tersebut cukup tinggi, yaitu sekitar 28.78 ppm. Penelitian lainnya Risma (2016) gorengan bakwan di pinggir jalan Kecamatan Tallo diperoleh kadar timbal $(\mathrm{Pb})$ yang terdapat dalam sampel berkisar antara 0,057 mg/kg - 1,537 mg/kg.

Sayuran termasuk tanaman yang mudah tumbuh pada lingkungan tercemar. Akibatnya, apabila terjadi pencemaran logam berat pada lingkungan, maka logam berat tersebut akan diserap melalui akar dan stomata daun dan selanjutnya terserap ke dalam jaringan tanaman. Jika tanaman tersebut dimakan oleh makhluk hidup lain, termasuk manusia, maka terjadilah proses penumpukan melalui siklus rantai makanan logam berat yang terakumulasi di dalam jaringan tubuh.

\section{2) Kandungan Timbal $(\mathrm{Pb})$ pada Gorengan Pisang di Kota Makassar}

Berdasarkan hasil analisis kandungan timbal $(\mathrm{Pb})$ yang di deteksi pada jajanan gorengan pisang. Hasil analisis kandungan timbal $(\mathrm{Pb})$ dalam jajanan gorengan di kota Makassar tidak memenuhi syarat, hal tersebut didasarkan pada ketentuan baku mutu kandungan logam berat pada cemaran mikroba dan kimia dalam makanan pada pangan olahan lainnya yaitu kandungan timbal $(\mathrm{Pb})$ sebagai pencemaran dalam pangan dan olahan lainnya maksimal 0,25 $\mathrm{mg} / \mathrm{kg}$ menurut Peraturan Kepala Badan Pengawasan Obat dan Makanan Republik Indonesia Nomor HK.00.06.1.52.4011.

Logam berat timbal $(\mathrm{Pb})$ dapat di jumpai di seluruh bagian alam, tetapi dengan kadar yang sangat rendah. Kadar logam berat timbal $(\mathrm{Pb})$ di lingkungan dapat berubahubah bergantung pada adanya perubahan dari kejadian alam, seperti hujan dan erosi, atau karena pencemaran dari berbagai aktivitas manusia.

Asap kendaraan sebagai hasil dari pembakaran bahan bakar yang mengandung bahan tambahan (additive) $\mathrm{Pb}$ dapat menghasilkan emisi $\mathrm{Pb}$ anorganik. Logam timbal $(\mathrm{Pb})$ yang telah bercampur dengan bahan bakar kemudian akan bercampur dengan oli. Selanjutnya melalui proses di dalam mesin kendaraan, logam berat timbal $(\mathrm{Pb})$ akan keluar dari knalpot bersama dengan gas buangan lainnnya. Pencemaran dari emisi gas buangan kendaraan ini menyumbang sekitar $65 \%$ dari pencemaran udara. ((Alsuhendra dan Ridawati, 2013)

Berdasarkan hasil penelitian Indah Ramadhana (2017) pengukuran udara timbal $(\mathrm{Pb})$ di udara yaitu di pasar Panampu kadar $\mathrm{Pb}$ yang didapatkan sebesar 0,65893 $\mu \mathrm{g} / \mathrm{Nm}^{3}$ sedangkan untuk jalan Urip Sumoharjo didapatkan sebesar 0,53510 $\mu \mathrm{g} / \mathrm{Nm}^{3}$. Logam timbal $(\mathrm{Pb})$ yang terbawa dari emisi asap kendaraan bermotor bersifat lipofilik (mudah berikatan dengan lemak) (Sartono, 2001), sehingga dapat meresap ke dalam gorengan. Seperti yang telah disebutkan sebelumnya, lokasi berdagang gorengan yang berada di sekitar persimpangan jalan raya merupakan salah satu faktor resiko tercemar oleh timbal. Hal ini dikarenakan banyaknya volume 
kendaraan bermotor mengeluarkan emisi asapnya. Darmono (1995) mengatakan, asap kendaraan bermotor menyumbang polusi udara sebesar $60 \%-70 \%$. Sehingga pada prinsipnya, baik pedagang maupun dagangan gorengannya sebenarnya berada pada kawasan resiko terpapar asap yang mengandung timbal $(\mathrm{Pb})$ setiap harinya.

Hasil penelitian Zukifli (2015), menyatakan kadar timbal $(\mathrm{Pb})$ pada jajanan di Kota Gorontalo yaitu Kandungan timbal pada jajanan pisang goreng berkisar antara $0,65 \mathrm{ppm}-3,86 \mathrm{ppm}$. Apabila gorengan tidak memenuhi syarat menimbulkan dampak terhadap kesehatan manusia yaitu dapat terjadi kerusakan pada system syaraf dan memungkinkan gangguan dalam system otak, timbal dapat merusak dengan berbagai cara seperti pengurangan sel-sel darah merah, penurunan sintesa hemoglobin dan penghambatan sintesa hemoglobin yang menimbulkan anemia (Wardhana, 2001).

Berdasarkan kandungan timbal $(\mathrm{Pb})$ yang di deteksi pada jajanan gorengan pisang. Hasil kandungan timbal $(\mathrm{Pb})$ dalam jajanan gorengan pisang pada lokasi jalan Daeng Tata adalah jumlah kadar $\mathrm{Pb}$ paling tertinggi yaitu $8,7637 \mathrm{mg} / \mathrm{kg}$ hal ini dapat disebabkan oleh salah satunya bahan baku yang digunakan mungkin mengandung timbal (Pb) contohnya pembuatan dan pengolahan jajanan gorengan pisang perendam mungkin kondisi air yang digunakan sudah mengandung timbal $(\mathrm{Pb})$ dan pada saat perendaman air tesebut terkontaminasi ke dalam pisang. Sedangkan faktor lain disebabkan oleh tingginya jumlah kendaraan yang lalu lalang terjadi kemacetan sedangkan kita ketahui kontaminasi timbal pada saat macet dibandingkan pada saat kendaraan bermotor tersebut jalan (tidak terjadi macet) bahwa komposisi persen dari total partikel timbal $(\mathrm{Pb})$ di dalam asap mobil sesaat setelah di macet lebih tinggi disbanding 18 jam setelah di macet kondisi kendaraan yang berhenti akan menimbulkan polusi udara yang mengeluarkan konsentrasi timbal lebih tinggi (Ardalina, 2013).

Adapun pengambilan sampel yaitu di jalan Lanto Dg. Pasewang kadar timbal $(\mathrm{Pb})$ $3,7499 \mathrm{mg} / \mathrm{kg}$ yang memiliki kadar kedua walaupun pada saat pengambilan sampel jalan tersebut tidak terlalu padat namun pada saat pengambilan sampel tersebut lama waktu gorengan tersebut sudah lama terpajan dan walaupun kurangnya kendaraan meningkatnya kadar timbal $(\mathrm{Pb})$ dapat dipengaruhi oleh jumlah kendaraan bermotor karena sumber utama timbal berasal dari pembakaran mesin kendaraan bermotor yang terdiri dari tertaetil $\mathrm{Pb}$ dan tertratil $\mathrm{Pb}$, polusi $\mathrm{Pb}$ yang terbesar dari pembakaran bensin, dimana dihasilkan berbagai komponen timbal $\mathrm{Pb}$ bahwa semakin banyak kendaraan yang lalu lalang konsentrasi timbal $(\mathrm{Pb})$ semakin meningkat pula.

Di lokasi ketiga, keempat dan kelima pengambilan sampel yaitu jalan Daya kadar timbal $(\mathrm{Pb})$ yaitu $1,0186 \mathrm{mg} / \mathrm{kg}$, jalan Minasa Upa kadar timbal yaitu $0,5573 \mathrm{mg} / \mathrm{kg}$, jalan Cendrawasi kadar timbal $(\mathrm{Pb}) 0,3071 \mathrm{mg} / \mathrm{kg}$ dimana kandungan timbal $(\mathrm{Pb})$ sangat dipengaruhi oleh jumlah kendaraan karena salah satu sumber utama adalah kendaraan bermotor sesuai yang dikemukakan (Palar,) Walaupun kendaraan yang melintas disana tidak sepadat di jalan Minasa Upa lokasi sampel yang paling tertinggi tapi tetap saja mengandung timbal $(\mathrm{Pb})$ walaupun tak sebanyak di lokasi tertinggi pertama.

Dan jalanan yang memiliki jumlah kadar timbal $(\mathrm{Pb})$ yaitu di jalan Datuk Patimang kadar timbal $(\mathrm{Pb})<0,10 \mathrm{mg} / \mathrm{kg} \mathrm{mg} / \mathrm{kg}$, di jalan Toddopuli kadar timbal $(\mathrm{Pb})$ yaitu < $0,10 \mathrm{mg} / \mathrm{kg}$ dan jalan Sunu kadar timbal $(\mathrm{Pb})$ yaitu $<0,10 \mathrm{mg} / \mathrm{kg}$ jumlah kadar timbal $(\mathrm{Pb})$ di ketiga lokasi tersebut merupakan lokasi jumlah kadar terendah dari semua lokasi, memiliki kadar timbal $(\mathrm{Pb})$ sebagai batas maksimum cemaran mikroba dan kimia dalam makanan maksimal $0,25 \mathrm{mg} / \mathrm{kg}$ menurut Peraturan Kepala Badan Pengawas Obat dan Makanan RI Nomor HK.00.06.1.52.4011.namun masih dibawah ambang batas yaitu $0,25 \mathrm{mg} / \mathrm{kg}$. hal tersebut dapat disebabkan dikarenakan gorengan tersebut baru saja diangkat dari kuali penggorengan dan saat itu masih sangat kurang kendaraan yang berlalu lalang. Dari hasil penelitian Astri W Hasbiah (2016) Pada Area Parkir Kampus Pasundan Bandung dapat disimpulkan kadar $\mathrm{Pb}$ di lokasi II terdeteksi paling tinggi sebesar 8,93 $\mu \mathrm{g} / \mathrm{Nm} 3$, sedangkan di lokasi III kadar $\mathrm{Pb}$ yang terdeteksi paling kecil sebesar 0,62 $\mu \mathrm{g} / \mathrm{Nm} 3$.

Adanya kadar timbal di dalam gorengan disebabkan oleh air yang digunaka pada saat proses pencucian bahan baku yang akan di goreng, kemungkinan besar juga dapat dipengaruhi oleh [adatnya kendaraan yang lalu lalang sehingga kadar timbal $(\mathrm{Pb})$ yang cukup tinggi sehingga terakumulasi di udara dan terabsosi masuk ke dalam gorengan tersebut. Dimana kandungan timbal $(\mathrm{Pb})$ sangat dipengaruhi oleh jumlah 
kendaraan karena salah satu sumber utama adalah kendaraan bermotor bawa emisi $\mathrm{Pb}$ yang masuk ke dalam bentuk gas, terutama berasal dari buangan kendaraan bermotor, emisi tersebut merupakan hasil samping dari pembakaran yang terjadi dalam mesin-mesin kendaraan. Proses timbal $(\mathrm{Pb})$ di udara yaitu bahan bakar bensin timbal $(\mathrm{Pb})$ yang digunakan oleh kendaraan sebagai bahan bakar. Proses pembakaran keluar melalui knalpot yang masuk ke lingkungan yang di predeksi masuk ke dalam jajanan gorengan.

Logam berat timbal $(\mathrm{Pb})$ yang masuk ke dalam tubuh manusia makanan akan terserap dalam aliran darah, setelah itu timbal akan di keluarkan dalam tubuh melalui fases dan urine, serta sisanya akan tersimpan di dalam tubuh terutama pada bagian tulang gigi (Wardhana dkk, 2001). Dan apabila gorengan tersebut masih memenuhi syarat akan juga menimbulkan gejala-gejala seperti bersifat kumulatif artinya keracunan akan timbul apabila kadar timbal $(\mathrm{Pb})$ dalam tubuh. Gejala yang timbul adalah muntah-muntah sekresi menyerupai sakit perut dan nyeri perut yang sangat hebat. Reaksi lain berbahaya yaitu reaksi alergi yang mengakibatkan iritasi dan pembengkakan kulit. Oleh karena itu gorengan yang di jual dipinggir jalan harus menggunakan penutup agar tidak terkontaminasi dengan debu dan asap kendaraan yang lewat sehingga tidak menimbulkan dampak bagi tubuh.

\section{3) Kandungan Timbal ( $\mathrm{Pb})$ pada Minyak Goreng di Kota Makassar}

Berdasarkan hasil analisis kandungan timbal $(\mathrm{Pb})$ pada minyak goreng ini masih memenuhi syarat sesuai dengan peraturan kandungan timbal $(\mathrm{Pb})$ dalam minyak goreng dikatakan memenuhi syarat jika hasil pemeriksaan menunjukkan jumlah maksimum $0,1 \mathrm{mg} / \mathrm{kg}$ sesuai dengan Standar Nasional Indonesia 01-3741-2002.

Secara umum kedelapan pedagang ini memiliki karakteristik yang hampir sama, di mana semuanya memiliki kebiasaan menggunakan minyak goreng bekas penggorengan sebelumnya, tidak memisahkan antara minyak bekas dengan baru pada saat penggantian minyak, tidak menggunakan minyak goreng berstandar SNI. Mereka juga tidak ada yang tahu bahwa batas maksimal penggunaan minyak goreng adalah dua kali, bahkan pedagang gorengan yang sama sekali tidak pernah mengganti minyak selama berdagang. Anggapan mereka ketika minyak masih dalam keadaan jernih walaupun berulang kali pakai, minyak tersebut masih dalam kondisi baik. Hal inilah yang diduga menjadi penyebab kadar peroksida pada sampel minyak yang diambil dari pedagang gorengan. Selain itu, tidak satupun dari pedagang ini yang mengetahui bahwa kontak langsung antara minyak dengan udara dapat mempercepat terjadinya proses ketengikan minyak, sehingga jika mereka menggunakan penutup saat penyimpanan minyak goreng, hanya untuk menghindari tumpahnya minyak tersebut. Namun demikian, seluruh pedagang gorengan ini mengetahui bahwa dengan menggunakan minyak bekas untuk menggoreng sama halnya dengan memakan zat beracun yang dibawa pada saat gorengan tersebut dikonsumsi dan berbahaya bagi kesehatan.

Minyak goreng curah merupakan minyak goreng yang dalam pembuatannya hanya mengalami sekali proses penyaringan, sehingga kadar lemaknya masih lebih tinggi dibandingkan minyak goreng kemasan. Hal itu mengakibatkan minyak goreng curah tidak baik dikonsumsi apabila sudah mengalami pengulangan pemakaian lebih dari dua kali. Faktor lain yang dapat mempengaruhi kadar bilangan peroksida minyak goreng adalah adanya kontak langsung dengan udara yang terkontaminasi bahan tertentu. Hal ini bisa terjadi pada saat pendistribusian minyak goreng dari pedagang ke konsumen. Wadah yang digunakan oleh pedagang untuk menyimpan minyak goreng curah biasanya berupa jerigen atau tong, yang di mana pada saat hendak dituangkan ke plastik, minyak goreng dibiarkan dalam keadaan terbuka selama beberapa saat sehingga mengalami kontak langsung dengan udara bebas.

Konsumsi makanan yang diolah dengan minyak goreng yang sudah mengalami ketengikan dalam jangka waktu lama dapat mengakibatkan timbulnya gangguan kesehatan, misalnya radang kerongkongan oleh zat akrolein, radang hati yang diakibatkan oleh jamur alatoksin, penyumbatan pembuluh darah bahkan mutasi gen oleh asam lemak tidak jenuh yang terkandung dalam minyak goring (Winarto, FG dan T.S. Rahayu.1994).

Dari data umum kondisi-kondisi yang bisa saja terkait dengan rendahnya kadar timbal pada minyak goreng. Hasil menunjukkan bahwa seluruh pedagang menjajakan dagangan gorengannya tepat di pinggir jalan raya yang ramai akan lalu lalang kendaraan bermotor dengan alasan 
lokasi tersebut sangat strategis, ramai dilalui, mudah dijangkau oleh calon pembeli dan tentunya menjadi kondisi yang bagus untuk mendatangkan keuntungan bagi mereka.

Hasil penelitian Sri Wulandari, dkk (2016) yang berjualan di pinggir Jl. R.E Martadinata Kota Palu kandungan timbal $(\mathrm{Pb})$ tertinggi pada minyak sebelum penggoengan adalah $0.0771 \mathrm{ppm}$ dan terendah adalah $0.0259 \mathrm{ppm}$. Ini berarti minyak goreng curah terdeteksi mengandung timbal $(\mathrm{Pb})$, sehingga perlu dipertimbangkan penggunaannya untuk menggoreng. Kandungan timbal $(\mathrm{Pb})$ tertinggi pada minyak sesudah penggorengan adalah $0.2562 \mathrm{ppm}$ dan terendah adalah $0.0985 \mathrm{ppm}$. Ini berarti pemakaian minyak untuk menggoreng di pinggir Jl. R.E Martadinatadapat meningkatkan kadar timbal (Pb) hingga melebihi batas maksimum. Kandungan timbal $(\mathrm{Pb})$ pada minyak sebelum penggorengan memenuhi syarat karna belum melebihi batas maksimum, kecuali minyak goreng sesudah penggorengan pedagang.

Para pedagang gorengan ada yang menggunakan minyak goreng kemasan sesuai standar dari SNI ataupun standar dari BPOM, karena seluruhnya menggunakan minyak goreng curah.Minyak ini ternyata mengandung logam timbal $(\mathrm{Pb})$ walaupun masih di bawah batas maksimum. Namun tetap saja perlu mendapat perhatian yang serius bagi Dinas Kesehatan Kota Palu atau BPOM untuk mengawasinya, mengingat banyaknya masyarakat yang menggunakannya untuk keperluan memasak sehari-hari. Seluruh pedagang memiliki kebiasaan menggunakan minyak curah dan tidak menyadari adanya timbal dalam minyak tersebut. Mereka lebih banyak menggunakan minyak curah karna terbilang murah dan mudah di dapatkan terutama di pasar.para pedagang gorengan tampak berusaha menjaga kondisi penggorengan dalam keadaan bersih, masih saja terdapat pedagang yang tidak membuat pelindung atau penghalang di sekitar penggorengan dari cemaran asap dan debu. Kegunaan pelindung atau penghalang sangat berkontribusi meminimalisir kandungan timbal $(\mathrm{Pb})$ dari udara yang bisa saja mencemari minyak goreng. Hal inilah yang tidak sejalan dengan sikap seluruh pedagang yang setuju memberi penghalang di sekitar kuali penggorengan agar tidak tercemar debu dan asap.
Berdasarkan penelitian Aryanto Purnomo (2017) kualitas udara ambien di lingkungan kerja pegawai UPTD Dinas Perhubungan Kota Pontianakdidapat kadar timbal $(\mathrm{Pb})$ di udara ambien berkisar antara $0,61-0,91 \mu \mathrm{g} / \mathrm{m} 3 / 5 j a m$, kadar timbal $(\mathrm{Pb})$ tersebut kondisinya masih berada di bawah nilai baku mutu.

Pedagang mengaku bahwa mereka menggunakan menggunakan campuran minyak goreng bekas penggorengan sehari sebelumnya dengan minyak goreng yang baru untuk penggorengan pertama kali setiap hari. Dalam hal ini, pedagang beranggapan bahwa minyak yang digunakan belum begitu buruk kualitasnya, sehingga untuk pemakaian pertama setiap harinya dapat digunakan kembali lalu dicampurkan dengan minyak goreng yang baru. Cara ini juga dinilai dapat menghemat minyak goreng yang akan digunakan untuk menggoreng.

Seluruh pedagang melakukan aktivitas penggorengan lebih dari 2 kali untuk setiap penggantian minyak goreng, karena menganggap bahwa warna minyak masih tampak bening, kotoran sisa penggorengan belum begitu banyak, sehingga kualitasnya dianggap masih baik dan layak digunakan hingga perubahan warna tampak benarbenar mencolok. Demikian untuk hal penggantian minyak, mereka semua mengaku tidak pernah memisahkan antara minyak bekas pakai dengan yang baru, langsung saja mereka menambahkan minyak goreng yang baru ke dalam wajan. Hal tersebut mereka lakukan dengan alasan tidak membuang waktu dan tenaga. Ketika ditanyakan mengenai penggunaan minyak goreng berulang dan hubungannya dengan gangguan kesehatan, seluruh responden menjawab tahu dan gangguan kesehatan yang diakibatkan adalah hanya kolesterol.

\section{KESIMPULAN}

Berdasarkan hasil penelitian yang telah diuraikan di atas, maka dapat disimpulkan sebagai berikut

1. Kadar timbal $(\mathrm{Pb})$ pada gorengan bakwan di Kota Makassar tidak memenuhi syarat menurut berdasarkan BPOM RI Nomor HK.00.06.1.52.4011 yaitu $0.25 \mathrm{mg} / \mathrm{kg}$.

2. Kadar timbal $(\mathrm{Pb})$ pada gorengan pisang di Kota Makassar tidak memenuhi syarat menurut berdasarkan BPOM RI Nomor HK.00.06.1.52.4011 yaitu $0.25 \mathrm{mg} / \mathrm{kg}$.

3. Kadar timbal $(\mathrm{Pb})$ pada minyak goreng yang digunakan oleh pedagang gorengan di Kota Makassar memenuhi syarat berdasarkan SNI 01-3741-2002 yaitu 0,1 mg/kg. 
Jurnal Sulolipu : Media Komunikasi Sivitas Akademika dan Masyarakat

Vol. 20 No. 12020

e-issn : 2622-6960, p-issn : 0854-624X

\section{SARAN}

Diharapkan kepada dinas terkait untuk memberikan penyuluhan kepada pedagang kaki lima terkhusus pedagang jajanan gorengan.

\section{DAFTAR PUSTAKA}

Alsuhendra dan Ridawati. 2013. Bahan Toksik dan Makanan. Jakarta : PT Remaja Rosdakarya

Anwar Azrul, Prihartono Joedo. 2014. Metodologi Penelitian. Tangerang : Binarupa Aksara Publisher. Anwar, dkk.1987.Pedoman Bidang Studi Sanitasi Makanan Dan Minuman.Pusat Pendidikan Tenaga Sanitasi Kesehatan Departemen Kesehatan RI.

Darmono. 1995. Logam Berat Dalam Sistem Biologi. Jakarta : UI Press.

Girsang, E. 2008. Hubungan Kadar Timbal di Udara Ambien dengan Timbal Dalam Darah pada Pegawai Dinas Perhubungan Terminal Antar Kota Medan.TESIS Paca Sarjana. Universitas Sumatera Utara. (Online). http://repository.usu.ac.id. (diakases pada 15 Mei 2019)

Indah Rahmadana. 2017. Analisis Konsentrasi Karbon Monoksida (CO) Dan Sulfur Dioksidasi $\left(\mathrm{SO}_{2}\right)$ Udara Pada Sumber Bergerak Di Jalan A.P. Pettarani Dan Jalan Rappocini Raya Kota Makassar.Politeknik Kesehatan Makassar Jurusan Kesehatan Lingkungan.SKRIPSI (Tidak dipublikasikan)

Palar, Heryando.1994. Pencemaran Dan Toksikologi Logam Berat.Jakarta : Rineka Cipta. (Online). https://www.coursehero.com. (Diakases pada 19 Desember 2018).

Rapotan Hasibuan. 2012 Analisa Kandungan Timbal (Pb) Pada Minyak Sebelum dan Sesudah Penggorengan yang digunakan Pedagang Gorengan Gorengan Sekitar Kawasan Traffic Light Kota Medan.Skripsi. Fakultas Kesehatan Masyarakat Universitas Sumatera Medan Utara.http://id.123.dok.com(diakses pada 13 Januari 2019)

Sediaoetama, A.D. 1989. IImu Gizi.Jakarta : Dian Rakyat.

Suci Anggraini. 2012. Faktor Lingkungan Dan Faktor Individu Hubungannya Dengan Konsumsi Makanan Pada Mahasiswa Asrama Universitas Indonsia Depok.Skripsi.Fakultas Kesehatan Masyarakat Universitas Indonesia Depok. (Online) http://lib.ui.ac.id(Diakses pada 10 Januari 2019)

Sudarmadji, J. Mukono, dan I.P. Corie. 2006. Toksikologi Logam Berat B3 dan Dampaknya Terhadap Kesehatan. Jurnal vol (5) No. 15. Kesehatan Lingkungan.http://www.journal.unair.ac.id(Diakses 23 Desember 2018)

Wardhana, W.A. 2001.Dampak Pencemaran Lingkungan. Yogyakarta: Penerbit Andi Yogyakarta.

Winarto, FG dan T.S. Rahayu.1994. Bahan Tambahan untuk Makanan dan Kontaminan.Jakarta : Pustaka Sinar Harapan 